\title{
Application of Nondestructive Testing in Inspection of Boiler and Pressure Vessel and Pressure Piping
}

\author{
Shuicai QIU, Lingyan ZHANG*
}

\begin{abstract}
Non-destructive testing technology has been widely used in all occupations. The testing of equipment is called non-destructive testing technology. During the testing process, there is no need to pre-process the equipment to test, nor add other testing substances, which is especially suitable for the testing of boiler equipment in industrial production. Boiler and pressure vessel equipment is an important part of industrial production. The boiler pressure vessel has been in an operating environment with relatively high temperature for a long time, and it is common for the boiler pressure vessel to rupture. At this time, non-destructive testing technology came into being. It can detect damage to the boiler structure without damaging it, which plays a vital role for boilers, especially pressure pipes. This article analyzes the advantages, disadvantages and principles of pressure pipeline non-destructive testing technology, and discusses its application in boiler flaw detection to provide guidance for future work.
\end{abstract}

Keywords: boiler equipment; flaw detection; non-destructive testing; pressure vessel

\section{INTRODUCTION}

With the continuous development of today's society and the continuous pursuit of energy technology, some companies use boilers and pressure vessels in their production more widely, such as thermal power plants. Due to the long-term internal operation of the boiler and pressure vessel and the continuous high temperature inside, if there is a crack inside, it is very easy to cause safety production accidents such as the explosion of the boiler and pressure vessel, which will cause damage to human life and corporate property [1]. Therefore, the inspection of boiler pressure pipes is very important. Non-destructive testing technology is widely used in boiler pressure pipeline, and it is currently one of the most commonly used effective methods for boiler pressure internal pipeline inspection. Non-destructive testing technology is a means of testing the performance of the internal materials and mechanical equipment of the boiler. It is an important part of testing whether the boiler pressure vessel has hidden safety hazards during long-term high temperature operation, and it is the key to ensuring the stable production and operation of the boiler. When testing the pressure of the internal pipes, it is necessary to ensure that the boiler pressure vessel will not be damaged, which requires the use of non-destructive testing methods.

Boiler pressure vessel is the full name of boiler and pressure vessel, because both belong to special equipment and occupy a very important position in daily production and life. It can be seen that the basic functions of the boiler is mainly the heat generated by burning fuel to provide sufficient heat energy for people's daily life and industrial production. During the long-term operation of boiler equipment, companies must regularly inspect the boiler pressure vessel to prevent potential safety hazards [2]. Non-destructive testing technology used to conduct daily inspections on the boiler can effectively improve the boiler operation security. Crack analysis is the basis of failure analysis. Through crack analysis, information such as the location of the crack source, the direction of propagation, the nature of the crack, the force state, and environmental conditions can be identified. The main task of boiler pressure vessel and pressure pipeline inspection is to detect defects in pressure parts, especially crack defects, to predict their safety performance level. The crack defect hidden in the pressure part may come from different processes such as manufacturing, processing, installation, and operation. It is the most unstable form of various defects and the main factor affecting the safety performance of the equipment. From the perspective of the weld itself, there are three main factors that determine the quality, which are the internal defects, the appearance and surface defects, and the size. Therefore, the weld quality level has two meanings, one is the inspection for internal defects of the weld, and the other is the inspection for the appearance and surface defects of the weld [3]. However, in most cases at present, designers only make general regulations. At this time, the correct understanding is "the internal defects of the weld are inspected as level 2, and appearance defects are also inspected as level 2. In crack analysis, in addition to observation with the naked eye and magnifying glass, non-destructive testing and metallographic low-power inspection methods can be used to show the morphology of cracks. Microscopic analysis mainly uses optical microscope and electron microscope to judge the nature, fracture path, and microscopic characteristics of cracks. The most common problem of boiler pressure vessel is weld quality. For non-destructive testing technology, it can conduct comprehensive testing of the mechanical equipment and materials used in the boiler, ensuring that the boiler can give full play to its performance, while also improving the safety of boiler operation. Because the boiler works in a high temperature environment for a long time, it has very high requirements for safety [4]. Therefore, it is necessary to ensure that the boiler pressure pipeline is inspected without destroying the boiler, which also reflects the need for the application of non-destructive testing technology.

To implement non-destructive inspection technology for boiler pressure pipes, it is necessary to calibrate the sensitivity of the inspection with a calibration instrument that uses analog source calibration. This article adopts the broken signal of a pencil lead of $2.5 \mathrm{~mm}$ in length. When the angle between the lead core and the pressure pipe of the boiler reaches $30^{\circ}$, the average value can be obtained, so that the sensitivity of the inspection can be grasped. When 
calibrating the pipeline sensitivity, the amplitude value generated during the acoustic emission of the analog source should be detected [5]. If the converter is $100 \mathrm{~mm}$ away from the analog source, the difference between any channel amplitude value and the average amplitude value of the channel will be less than $4 \mathrm{~dB}$. After the nondestructive testing of the pressure pipe, the number of acoustic emission impacts should be observed, the changes in load and time should be judged, the results obtained by the testing, and the differences in the testing results should be compared. If the number of acoustic emission affects rapidly, both loading and pressurization need to stop. After the non-destructive testing, if there is noise, to avoid the interference of the test result by the noise, it is necessary to stop the test immediately to eliminate the noise. After confirming that there is no noise, the test can be continued.

\section{INSPECTION CONTENT AND RELATED METHODS 2.1 Main Factor of Boiler Pressure Pipe Damage}

In the inspection of boiler pressure vessel and pressure pipeline, the most critical link is to check whether the pipeline has cracks, which is the basic content that affects the normal operation of boiler equipment [6]. If the boiler is used for a long time and continuously, without paying attention to regular maintenance and maintenance, it is very easy to cause damage to the internal materials. If some parts are aging, corroded, and damaged, it will seriously affect the actual quality of the internal container. This will further affect its normal work efficiency and cannot meet the needs of the work [7]. If it is used continuously without overhaul, it is likely to cause damage that is more serious and damage to the boiler and cause a safety accident. In this work, the staff must scientifically summarize the common types of cracks and the causes of such cracks, and scientifically formulate prevention and solutions.

1) Cracks in the early installation process.

In the previous boiler pressure pipe installation, the factors that cause cracks can be divided into two types, namely the material itself and the employee's pipe installation behavior. If the pipeline material has quality problems in terms of corrosion, uneven surface, and insufficient heat resistance, it is easy to cause safety hazards and cracks [8]. At the same time, from the perspective of human factors, due to the continuous expansion of boiler enterprises, the corresponding pressure pipeline lines are also gradually increasing. In view of the basic layout of the city, sometimes during the pipeline installation process, reasonable bending operations of the pipeline are also involved. The difficulty of this work is relatively high. If the working ability of the operators is not in place, it is easy to cause gaps in the pipeline connection due to sloppy installation and operation.

2) Crack problems during later use.

After the completion of the pipeline installation work, the company must regularly inspect the operating status of the pressure pipeline and discover the gaps in the pipeline in time to solve the safety risks in the work process. Based on actual work experience, it can be found that the most common cracks in boiler pressure vessel pressure pipelines are fatigue cracks. Fatigue cracks mainly include two types: corrosion fatigue cracks and mechanical fatigue cracks. Mechanical cracks mostly occur in places where the pipeline is relatively stressed, and the cracks change from small to large, which requires the staff to pay attention to whether the pipeline has uneven forces. The reason for the formation of corrosion fatigue cracks is that the original fatigue cracks are subjected to the dual effects of corrosive media and alternating stress, which ultimately leads to the formation of corrosion cracks from fatigue cracks. The characteristic of this kind of crack is that as time goes by and the working frequency of boiler equipment increases, the length of the crack will gradually expand.

\subsection{Ultrasonic Inspection}

The ultrasonic inspection method is used to carry out the non-destructive inspection of the boiler and pressure vessel. The principle is to use the reflection property of the interface that occurs during the propagation of the medium to realize the defect inspection [9]. This method has high sensitivity, strong penetrating power, and high inspection efficiency. Features and the ultrasonic flaw detector equipment have the characteristics of lightweight, harmless to human body, and small size, as shown in Fig. 1. It can quickly inspect the defects of pressure vessels, pipelines, or boilers. It is currently widely used in the safety assessment of pressure vessels, boilers and other fields. Usually newly installed pressure vessels, pipelines, or boilers will use X-rays for random inspections. However, for the inspection and inspection of pressure vessels and pipelines that have been in operation or in use, X-rays may be restricted by underground operations and aerial operations in some cases. Therefore, ultrasound is more suitable for the inspection of pressure vessels and pipelines that have been used.

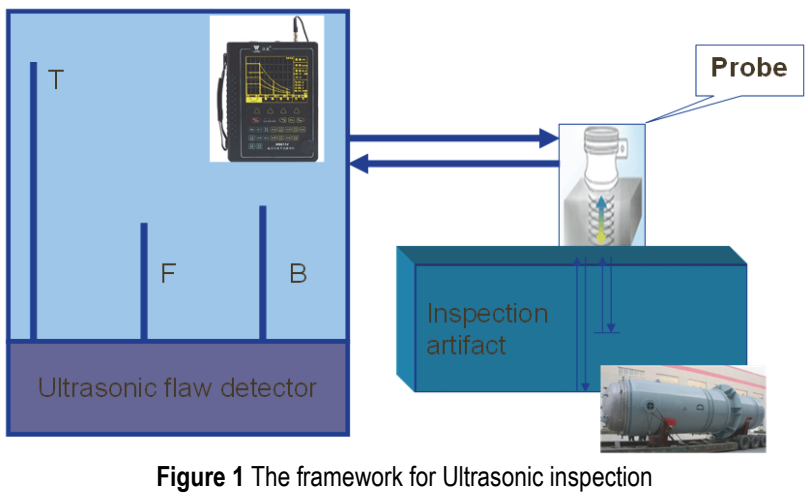

In the application process of ultrasonic detection technology, ultrasonic instruments are mainly used. In the process of inspecting the boiler pipe, the ultrasonic wave will enter the boiler [10]. If the ultrasonic wave receives resistance and returns during the inspection, it means that there is a crack in the boiler pipe. In addition, the approximate location of the pipeline defect can be determined according to the ultrasonic response time, which provides convenience for subsequent maintenance work. The cost of this technology is relatively small, the operation is convenient, it is also convenient to carry, and it will not affect the human body of the operator. 
3 THE APPLICATION OF NON-DESTRUCTIVE INSPECTION TECHNOLOGY IN BOILER PRESSURE VESSEL INSPECTION

\subsection{Process of Non-Destructive Testing}

Ultrasonic non-destructive testing of defect height and inclination can be measured by endpoint diffraction wave method or endpoint maximum wave height method. When the end-point diffraction wave or the maximum reflection wave of the defect cannot be found during the measurement, the $6 \mathrm{~dB}$ method can be used for measurement in Fig. 2. When the height of the defect itself is measured by the $6 \mathrm{~dB}$ wave, the defect height should be appropriately corrected.

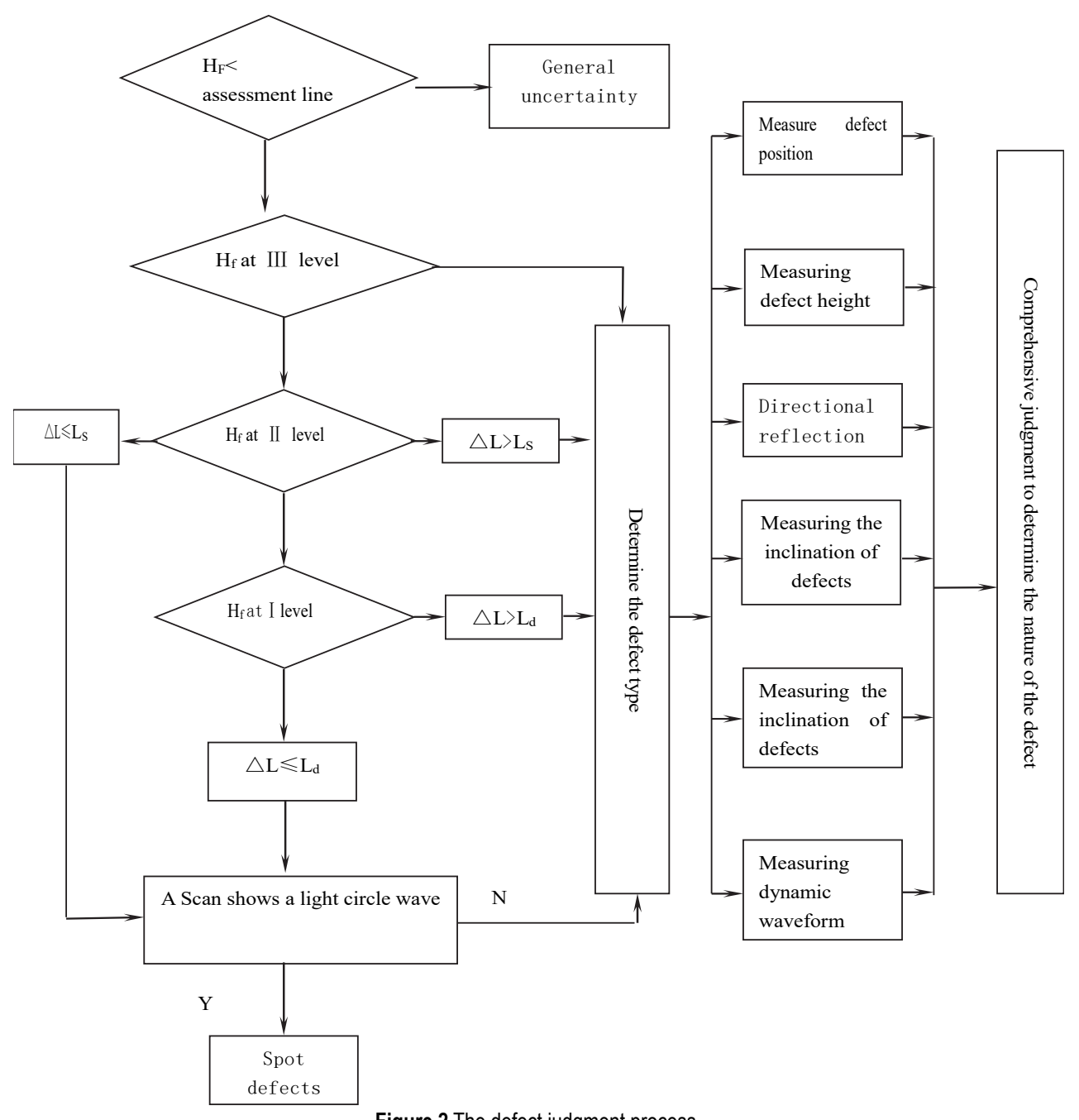

Figure 2 The defect judgment process

1) Preparation:

Before the inspection, the inspector should conduct a comprehensive observation of the on-site environment. If there is noise, it is necessary to find the source of the noise and eliminate it. In general, the cause of noise is usually electromagnetic interference, fluid flow, such as vibration and friction. If you want to eliminate the noise, you must find the cause. When searching, you can determine the sound source through the pressure program, and then remove the noise according to the actual situation.

2) Calibration:

In order to improve the accuracy of non-destructive inspection results, it is necessary to use advanced and highstandard instruments for calibration, so that the sensitivity of the inspection technology can be calibrated [11]. When calibrating, you can use the forearm refill with a length of $2.5 \mathrm{~mm}$ as a signal for breaking. If the angle between the pressure management in the pot and the pencil refill reaches $30^{\circ}$, it is possible to obtain an accurate average value, which is more adequate to grasp the sensitivity of inspection technology.

3) Inspection process:

When using non-destructive inspection technology to inspect the pressure pipe of the boiler, it is necessary to observe the number of impacts emitted, and to accurately judge the changes in time and load, which obtain the test results and compare the differences in the test results. If the number of impacts increases rapidly, it is necessary to immediately stop pressurizing and loading. In addition, if noise occurs during the detection, the detection needs to stop immediately, and the detection cannot continue until the noise is eliminated.

\section{4) Evaluation:}

Acoustic emission sources are classified according to grades. The specific grades are divided into activity grades and intensity grades. After the grades are determined, the sound source is divided again according to the vitality of the sound source. Not only the speed will continue to 
increase with the increase in pressure, but also the acoustic emission of source events will increase, which is enhancing the activity of the acoustic emission source, to obtain various amplitude parameters and indicators.

\subsection{Boiler Pipeline Weld Inspection}

In this paper, a boiler-heating pipeline with a length of $15.30 \mathrm{~km}$, an operating pressure of $2.0 \mathrm{MPa}$, a pipe diameter of $377 \mathrm{~mm}$, and a wall thickness of $10 \mathrm{~mm}$ is selected for pipeline weld inspection [12]. In order to ensure that the pipeline inspection meets the requirements of the regulations, the artificial defect specimens are made as the basis for the weld quality inspection.

The pipeline is at the diameter of $377 \mathrm{~mm}$, a wall thickness of $10 \mathrm{~mm}$, and a length of $250 \mathrm{~mm}$. In the welding stage, defects such as incomplete penetration, pores, and slag inclusion occurred artificially. The defects of the test pipeline are shown in Tab. 1.

\begin{tabular}{|c|c|c|c|}
\multicolumn{2}{c}{ Table 1 Test pipeline defects } \\
\hline Defect description & $\begin{array}{c}\text { Unwelded } \\
\text { part / mm }\end{array}$ & $\begin{array}{c}\text { Air control } \\
\text { part / mm }\end{array}$ & $\begin{array}{c}\text { Slag inclusion } \\
\text { part / mm }\end{array}$ \\
\hline Defect length & 50 & 4 & 10 \\
\hline Distance from surface & 8 & 5 & 6 \\
\hline
\end{tabular}

(2) Ultrasonic flaw detector preparation.

This article adopts CTS-26 ultrasonic flaw detector, the test block uses CSK-IA, CSK-IIIA, as the stage of debugging the instrument. According to JB/T 4730.1-2005 "pressure vessel non-destructive testing" ultrasonic inspection for $\mathrm{K} 2$ probe incident point test, this paper adjusts the horizontal scanning distance at a ratio of $1: 1$, and makes the distance as the amplitude curve, set the inspection sensitivity, which sets the $4 \mathrm{~dB}$ surface roughness compensation and the decibel value of the curved surface compensation.

\begin{tabular}{|c|c|c|c|c|}
\hline \multirow{2}{*}{ 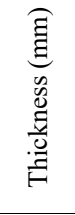 } & \multirow{2}{*}{$\begin{array}{l}0 \\
0 \\
0 \\
0 \\
\mathscr{0} \\
0\end{array}$} & \multirow{2}{*}{ 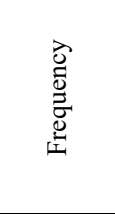 } & \multicolumn{2}{|c|}{ Probe chip size } \\
\hline & & & $\begin{array}{l}\text { Dual element } \\
\text { probe }\end{array}$ & $\begin{array}{l}\text { Single crystal } \\
\text { straight probe }\end{array}$ \\
\hline $6-10$ & $\begin{array}{c}\text { Dual } \\
\text { element } \\
\text { probe }\end{array}$ & $5 \mathrm{MHz}$ & $\begin{array}{c}\text { The chip area is } \\
\text { not less than } \\
150 \mathrm{~mm}^{2}\end{array}$ & - \\
\hline $\begin{array}{l}10- \\
250\end{array}$ & $\begin{array}{l}\text { Single } \\
\text { crystal } \\
\text { straight } \\
\text { probe }\end{array}$ & $2.5 \mathrm{MHz}$ & - & $\begin{array}{c}\text { The diameter of the } \\
\text { round wafer is } 14 \text { - } \\
25 \mathrm{~mm} \text {, or the area } \\
\text { of the square wafer } \\
\text { is not less than } 200 \\
\mathrm{~mm}^{2}\end{array}$ \\
\hline
\end{tabular}

(3) Polish the detection surface. The newly delivered steel is free of corrosion and no grinding operation is required. Although the pressure pipeline of the boiler that has been used for a long time is equipped with anticorrosion and heat preservation measures, there is still a certain degree of corrosion. Therefore, the surface roughness $R a=6.3 \mu \mathrm{m}$ should be guaranteed during the inspection stage.

(4) Carry out inspections. Before the flaw detection and inspection, the weld inspection of the manual test pipeline should be carried out first, followed by the inspection of the $15.3 \mathrm{~km}$ boiler pressure pipeline. After inspecting the supply of 2642 butt joints other than the fillet weld, the qualified rate of the pipeline was only $31.7 \%$, there are 1830 butt joints where the roots of the butt joints are not penetrated, and the most serious part is $150 \mathrm{~mm}$.

After the defects were discovered, physical anatomy inspections were carried out, and it was found that there were indeed a large number of severe joints at the root that were not penetrated, with a depth of 4 to $5 \mathrm{~mm}$ from the surface. These joints with excessive defects would inevitably seriously affect the normal operation of the boiler pressure pipeline. This inspection uses the ultrasonic inspection method to achieve non-destructive inspection on the pressure pipeline of the boiler in use with a length of $15.3 \mathrm{~km}$, and effectively found that the roots of $1830 \mathrm{butt}$ joints are not penetrated, which fully demonstrates that the ultrasonic inspection method is very suitable for the inspection of boiler pressure pipelines. It can be widely used in the daily maintenance and maintenance of boiler pressure pipelines [9].

\subsection{Inspection of Boiler Heat Exchanger in Use/Production}

A non-destructive inspection of the shell and tube heat exchanger made of carbon steel in a boiler unit was carried out. The specifications of this batch are cylinder $16 \mathrm{MnR}$, tube sheet $16 \mathrm{MnIII}$, tube 10\#, design temperature $10 / 200{ }^{\circ} \mathrm{C}$. During the phase of heat exchanger use, the fault is manifested as internal leakage. After stopping the equipment, open the upper and lower pipe boxes, and visually observe that there are many corrosion pits in the upper and lower tube plates. In order to inspect the detailed leakage position, firstly use the soap bubble inspection method and the ammonia leak detection to carry out the inspection and find the basis for cracks. The penetration inspection technology under non-destructive inspection, and the magnetic particle inspection technology are used in turn to carry out defect inspection.

In the penetration inspection stage, evenly apply a special liquid to the upper tube sheet, lower tube sheet and all pipe-tube sheet fillet welds with surface cracks found through the ammonia leak detection and soap bubble inspection methods, and wait for the special liquid to penetrate. After the defective part of the heat exchanger, the inspector visually found that about $50 \%$ of the pipetube plate fillet welds on the upper tube plate of the heat exchanger had cracks. After the penetration test is completed, the magnetic particle inspection is carried out, and the magnetic powder is evenly applied to the parts where surface cracks are found based on the ammonia leak detection and soap bubble inspection methods. According to the scale, shape and position of the traces after magnetic particle adsorption, almost all tube end corners of the upper tube plate are judged. There are cracks in the welds, and even a part of the fillet weld cracks at the pipe end have extended to the inner surface of the tube sheet and the pipe end [10].

For the non-destructive inspection of the boiler heat exchanger, firstly, the nature and location of the defect were obtained based on the actual operating conditions of the equipment, that is, the failure performance and preliminary inspection methods. Then the penetration inspection and magnetic particle inspection methods were 
used to carry out the work in turn, and the inspection results Demonstration of the two methods can accurately, comprehensively and intuitively reflect the specific conditions of the boiler heat exchanger defects in use, and quickly determine the root cause of the defects. The test results show that magnetic particle inspection has higher sensitivity and accuracy than penetration inspection.

\subsection{Inspection of Boiler Heat Exchanger in Production}

During the production stage of boiler equipment, it was discovered that a boiler tube and shell heat exchanger in manufacturing had tube-side leakage. Visual and macro observation revealed that there were burning perforations in the welds of the tube-tube sheet of the heat exchanger. The production team united after analysis, it was concluded that the burn-through holes in these pipe-tube sheet welds were caused by improper welding operations. Then, it was decided to use ultrasonic inspection to carry out nondestructive inspection work on all welds of the heat exchanger to facilitate timely detection of incomplete burnthrough holes.

In the inspection stage, the equipment adopts ultrahigh frequency, microchip ultrasonic phased array technology, assisted by mechanical transmission technology, and uses a circumferential stepper motor to carry out circumferential scanning. Recording and displaying are performed at the same time during the scanning stage.

During the scanning process, the space scan is carried out according to the planned path. The ultrasonic phased array detector uses the encoder to obtain the ultrasonic signal obtained by the position probe, and uses computer processing to form a 3D real-time image, combined with the software of the equipment to determine the length of the defect area by wave amplitude. The schematic diagram of ultrasonic phased array inspection technology is shown in Fig. 3.

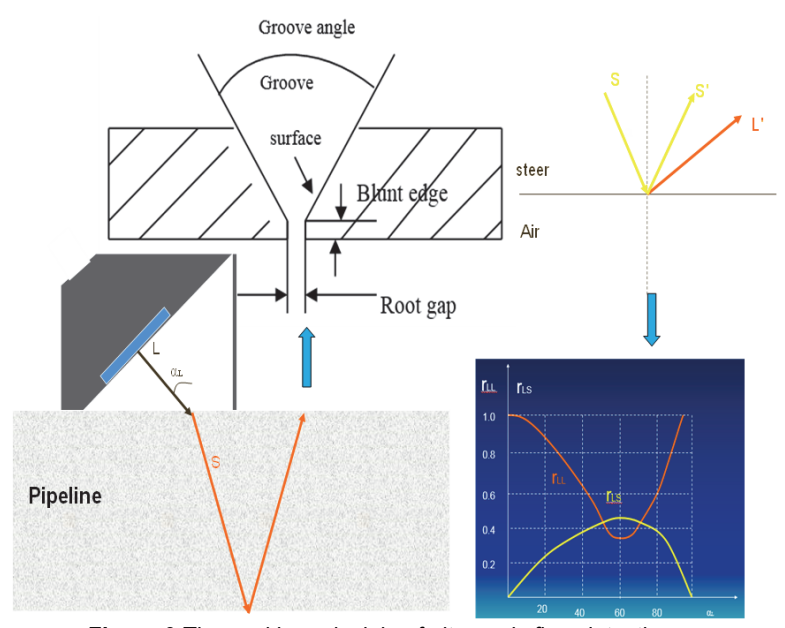

Figure 3 The working principle of ultrasonic flaw detection

In the ultrasonic inspection stage, the pipe-tube sheet weld inspection is carried out with an ultrasonic phased array. During the inspection, the probe is extended into the weld area of the pipe mouth to perform a $360^{\circ}$ circumferential scanning inspection. The ultrasonic phased array inspection diagram is shown in Fig. 4.

In the inspection stage, the probe is placed on the central axis of the pipeline, the ultrasonic wave enters the steel based on water, and the propagation of the sound beam is controlled by the delay method. So that the ultrasonic waves emitted by all the lenses are transmitted to a given point at the same time, and a focused sound field is formed at the given point. The equipment is arranged. The stage wafers are arranged axially along the tube, and after the inspection starts, the electronic wire is used for scanning until the entire probe scans the tube.
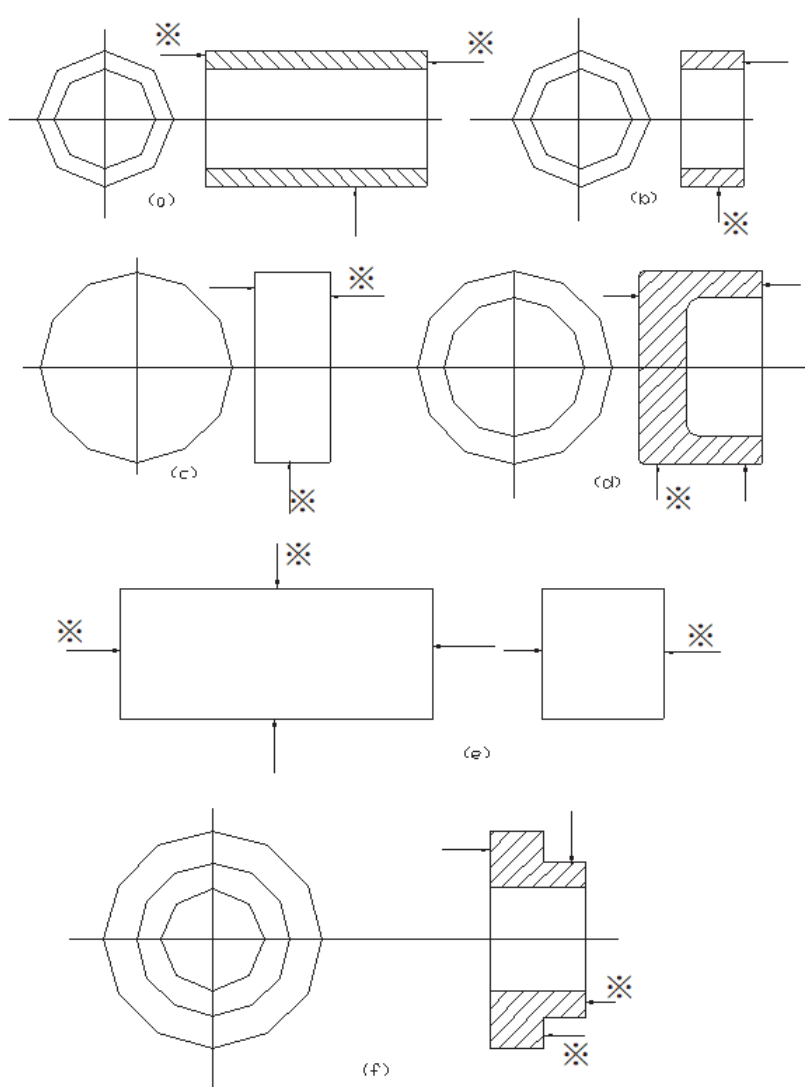

Figure 4 The ultrasonic phased array inspection

This experiment uses an ultrasonic phased array to conduct non-destructive inspection of the boiler heat exchanger under manufacture, and quickly and accurately detects the defects in the root of the fillet weld, that is, the hole that is not completely burned through, as shown in Fig. 5.

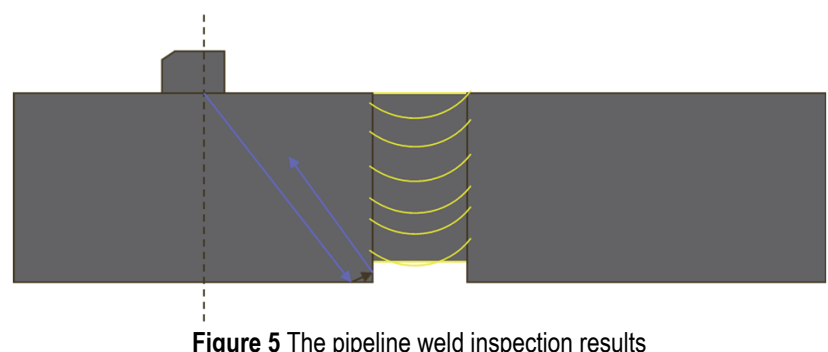

It can be seen from Fig. 3 that ultrasonic testing technology can quickly and accurately inspect the defects and properties of boiler pressure vessels, and is an effective means for daily maintenance and maintenance of boiler pressure vessels and pipelines [13]. 


\subsection{Longitudinal Wave Oblique Incident on Pressure Pipeline Test}

Fig. 6 shows the relationship between the reciprocating transmittance of sound pressure and the angle of incidence when longitudinal waves are oblique incidents on the pressure pipe. When the longitudinal wave incidence angle $\alpha_{\mathrm{L}}<14.5^{\circ}(\alpha \mathrm{I})$, the reciprocating transmittance TLL of refracted longitudinal waves does not exceed $13 \%$, and the reciprocating transmittance TLS of refracted transverse waves is less than $6 \%$. When $\alpha_{\mathrm{L}}<14.5^{\circ} \sim 27.27^{\circ}(\alpha \mathrm{II})$, there is no refracted longitudinal wave in the steel, only refracted transverse wave, and the reciprocating transmittance TLS of the refracted transverse wave is up to less than $20 \%$. This is the case for steel in water immersion testing in actual testing.

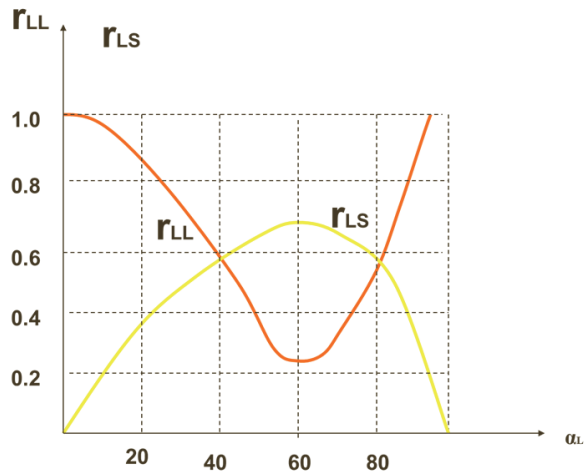

Figure 6 The Longitudinal wave incident on pressure pipeline test

As shown in the figure, when longitudinal waves are oblique incidents on the pressure pipe, the longitudinal wave sound pressure reflectivity $r_{\mathrm{LL}}$ and the transverse wave sound pressure reflectivity $r_{\mathrm{LS}}$ change with the incident angle $\alpha_{\mathrm{L}}$. When $\alpha_{\mathrm{L}}=$ about $60^{\circ}, r_{\mathrm{LL}}$ is very low and $r_{\mathrm{LS}}$ is very high. The reason is that longitudinal waves are incident obliquely, and when $\alpha_{\mathrm{L}}=60^{\circ}$, a strong deformed reflected transverse wave is produced.

\subsection{Obliquely Incident Transverse Wave to Pressure Pipeline Test}

Fig. 7 shows the relationship between the reciprocating transmittance and the angle of incidence when longitudinal waves are obliquely incident on a pressure pipe. When $\alpha_{\mathrm{L}}$ $<27.6^{\circ}(\alpha \mathrm{I})$, the reciprocating transmittance TLL of refracted longitudinal waves does not exceed $25 \%$, and the reciprocating transmittance TLS of refracted transverse waves is less than $10 \%$. When $\alpha_{\mathrm{L}}<27.6^{\circ} \sim 57.7^{\circ}(\alpha \mathrm{II})$, there are only refracted transverse waves in steel, but no refracted longitudinal waves. The reciprocating transmittance TLS of refracted transverse waves does not exceed $30 \%$. At this time, the corresponding $\alpha_{\mathrm{L}} \approx 30^{\circ}$ and $\beta_{\mathrm{S}} \approx 37^{\circ}$. In actual testing, this is the case when the plexiglass transverse wave probe detects steel.

As shown in the figure, the transverse wave is incident on the pressure pipe obliquely, and the transverse wave sound pressure reflectance $r_{\mathrm{SS}}$ and longitudinal wave sound pressure reflectance $r_{\mathrm{SL}}$ vary with the incident angle. When $=30^{\circ}, r_{\mathrm{SS}}$ is very low and $r_{\mathrm{SL}}$ is high. When $\geq 33.2^{\circ}(\alpha \mathrm{III})$, $r_{\mathrm{SS}}=100 \%$, that is, total reflection of steel type transverse wave.

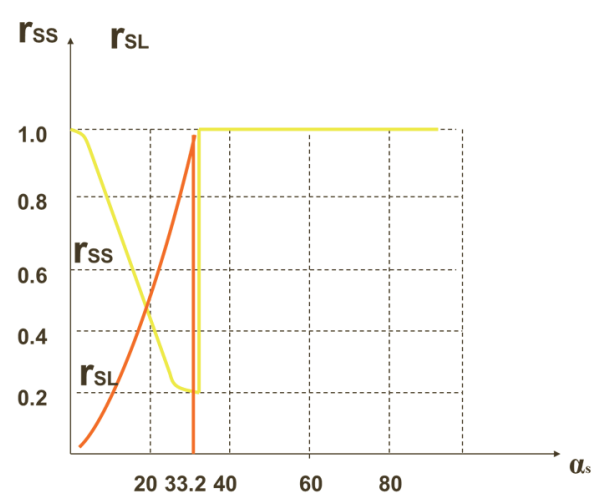

aII

Figure 7 The transverse wave to pressure pipeline test

\subsection{Grade Assessment of Pressure Pipeline Defects}

Through the above tests, using a thin plate test with a thickness of $6 \mathrm{~mm}$ and a $2 \times 20$ long horizontal hole, referring to the GB/T4730-2005 standard distanceamplitude curve sensitivity, the weld seam of the thin plate (thickness) with a thickness of less than $8 \mathrm{~mm}$ is feasible.

The $6 \mathrm{~mm}$ thin plate test block is easy to use, light in weight, suitable for high altitude, easy to make, one adjustment can be used for welding of various thicknesses, and the positioning error is small. The test error is about $1 \mathrm{~mm}$.

According to actual welding plate detection test, the reflected wave with pores above $1.5 \mathrm{~mm}$ and incomplete penetration above $0.8 \mathrm{~mm}$ reaches or exceeds the quantitative line.

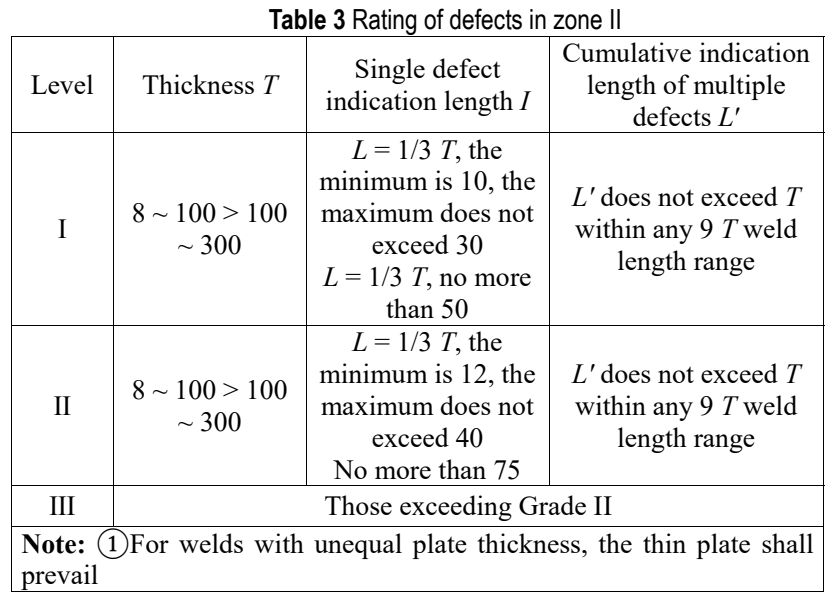

The first-level weld inspection ratio is $100 \%$, that is, full inspection; the second-level weld inspection ratio is $20 \%$. For factory-made welds, the ratio should be calculated based on the length of each weld, and the inspection length $\geq 200 \mathrm{~mm}$, when the length of the weld is less than or equal to $200 \mathrm{~mm}$, the entire weld shall be inspected for flaws; for on-site installation welds, the proportion shall be calculated based on the welds number of the same type and welding conditions, and the flaw detection length shall be $\geq 200 \mathrm{~mm}$, and no less than 1 weld. The third-level weld does not require non-destructive inspection of internal defects. When the length of the welds produced by the factory is less than or equal to $1000 \mathrm{~mm}$, each weld is 1 . When the length is greater than $1000 \mathrm{~mm}$, it is divided into 1 for each $300 \mathrm{~mm}$, and each weld for the 
on-site installation weld is 1 .

If the number of welds in the sampling inspection is less than $2 \%$, the batch acceptance shall be regarded as qualified; if the failure rate is more than $5 \%$, the sampling inspection shall be doubled, and the welding on both sides of the original unqualified part increases the seam extension line by 1 point. If the unqualified rate of all the random welds is less than or equal to $3 \%$, the batch acceptance shall be regarded as qualified, and if it is $>3 \%$, the batch acceptance shall be regarded as unqualified. When the batch acceptance is unqualified, all the remaining welds of the batch shall be inspected.

\section{CONCLUSIONS}

Ultrasonic flaw detection technology is used in boiler manufacturing and assembly process and later monitoring and inspection process with its unique advantages. Its monitoring standards include qualification level, flaw detection ratio and expansion requirements and other indicators have corresponding technical regulations. This article makes an in-depth exploration of the application of non-destructive inspection technology for boiler pressure vessels, introduces in detail the ultrasonic inspection, penetrant inspection, and magnetic particle inspection in the non-destructive inspection technology. Based on case analysis, it demonstrates the application methods and effects of non-destructive inspection technology in boiler pressure vessel. In actual production, boiler unit managers should strengthen the supervision of boiler pressure vessel, and refer to the application method of non-destructive testing proposed in this article based on timely detection of defects, to determine the pressure vessel defect to ensure the boiler pressure. The container is always in a safe and stable operating state, brings stable economic benefits to the enterprise.

\section{Acknowledgments}

The work is supported by Jiangsu Qing Lan Project; Jiangsu 333 Project.

\section{REFERENCES}

[1] Gezaei, A. A., Sung-Jin, S., Hak-Joon, K., Kishore, M. B., Teak-Gyu, L., \& Sung-Sik, K. (2018). Prediction of grain orientation in dissimilar metal weld using ultrasonic response of numerical simulation from deliberated scatterers. International Journal of Pressure Vessels and Piping, 168, 110. https://doi.org/10.1016/j.jpvp.2018.09.001

[2] Park, I. C., Kim, S. C., Shin, J. Y., Jung, H. C., \& Kim, K. S. (2018). Defect inspection of pressure piping using multiple laser diodes. Journal of the Korean Society for Nondestructive Testing, 38(2), 91-97. https://doi.org/10.7779/JKSNT.2018.38.2.91

[3] Prasetyo, E., Pariaman, H., \& Sulistijono. (2020). Tangential $\mathrm{x}$-ray radiography for pitting geometry analysis of outside wall of insulated steel pipes. Russian Journal of Nondestructive Testing, 56(3), 249-258. https://doi.org/10.1134/S1061830920030031

[4] Fukuda, K., Nishimura, Y., Suzuki, T., Ikeda, E., \& Uchibe, G. (2016). 612 visualization of internal defects by electromagnetic ultrasonic flaw detection method (4th report). The Proceedings of Conference of Chugoku-Shikoku Branch, 2016.54, 612-1-612-2. https://doi.org/10.1299/jsmecs.2016.54.612-1

[5] Song, Y., Turner, J. A., Peng, Z., Chao, C., \& Li, X. (2018). Enhanced ultrasonic flaw detection using an ultrahigh gain and time-dependent threshold. IEEE Transactions on Ultrasonics Ferroelectrics \& Frequency Control, 1-1. https://doi.org/10.1109/TUFFC.2018.2827464

[6] Jia, X. (2016). Discussion on causes and preventive measures of disqualified $30 \mathrm{crmo}$ alloy steel plate in ultrasonic flaw detection. Wide and Thick Plate, 022(003), $25-28$.

[7] Corporation, J. S. (2016). Ultrasonic flaw detection method and ultrasonic flaw detection apparatus.

[8] Wang, M., Wang, B., \& Zhang, Q. (2020). Study on the application of ultrasonic flaw detection to the monitoring of deep water steel cofferdam. IOP Conference Series: Materials Science and Engineering, 780(6), 062025 (7pp). https://doi.org/10.1088/1757-899X/780/6/062025

[9] Du, T., Sun, J., Fu, S., Zhang, C., \& Gao, Q. (2017). Research on ultrasonic flaw detection of steel weld in spatial grid structure. IOP Conference, 216. https://doi.org/10.1088/1757-899X/216/1/012016

[10] Xue, S. N., Le, Q. C., Jia, Y. H., Jiang, L. P., Zhang, Z. Q., \& Bao, L. (2019). Ultrasonic flaw detection of discontinuous defects in magnesium alloy materials. China Foundry. https://doi.org/10.1007/s41230-019-9041-6

[11] Ha, S. K., Lee, S. W., Jeon, W., \& Baek, K. R. (2018). Multichannel ultrasonic flaw detection system for oil country tubular goods. Journal of Institute of Control, 24(1), 90-95. https://doi.org/10.5302/J.ICROS.2018.17.0164

[12] Zhang, Q. \& Chen, C. (2018). An analysis of excitation pulse adjustable signal of ultrasonic flaw detection. Russian Journal of Nondestructive Testing, 54(7), 510-518. https://doi.org/10.1134/S1061830918070100

[13] Mogilner, L. Y. \& Smorodinskii, Y. G. (2018). Ultrasonic flaw detection: adjustment and calibration of equipment using samples with cylindrical drilling. Russian Journal of Nondestructive Testing, 54(9), 630-637. https://doi.org/10.1134/ S106183091809005X

\section{Contact information:}

\section{Shuicai QIU}

Changzhou University Huaide College, Jingjiang, 214500, P. R. China Jiangsu Key Laboratory of Green Process Equipment Changzhou, 213164, P. R. China

E-mail: qiushuicai_czuh@163.com

\section{Lingyan ZHANG}

(Corresponding author)

Changzhou University Huaide College,

Jingjiang, 214500, P. R. China

Jiangsu Key Laboratory of Green Process Equipment,

Changzhou, 213164, P. R. China

E-mail: zhanglingyan_czuh@163.com 